\title{
[RETRACTED ARTICLE] \\ Distribution and association between environmental and clinical isolates of Cryptococcus neoformans in Bogotá-Colombia, 2012-2015
}

Norida Vélez, Patricia Escandón/+

Grupo de Microbiología, Instituto Nacional de Salud, Bogotá, Colombia

Following authors' decision, the article "Distribution and association between environmental and clinical isolates of Cryptococcus neoformans in Bogotá-Colombia, 2012-2015" published in Memorias do Instituto do Oswaldo Cruz 111(10):642-648, 2016, DOI: 10.1590/0074-02760160201, authored by N Vélez \& P Escandón was retracted due to an authorship conflict.

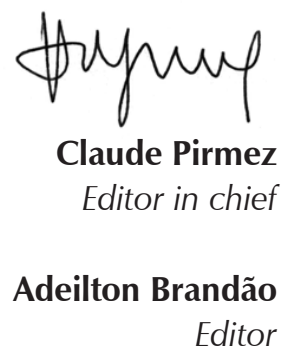




\title{
Distribution and association between environmental and clinical isolates of Cryptococcus neoformans in Bogotá-Colombia, 2012-2015
}

\author{
Norida Vélez, Patricia Escandón/+ \\ Grupo de Microbiología, Instituto Nacional de Salud, Bogotá, Colombia
}

\begin{abstract}
The propagules of the fungal species Cryptococcus neoformans and C. gattii, whose varieties are distriby dyorld wide, are the primary cause of cryptococcosis, a life threatening disease. The study of environmental an hica' isolates of Cryptococcosis is an important contribution to the epidemiology and ecology of the fungus. The aln if work was to determine the presence of $\mathrm{C}$. neoformans and $\mathrm{C}$. gattii in the environment in Bogotá, $\mathrm{C}$ ' $\mathrm{Vmbia}$ 's cupital city and to establish the relation between clinical and environmental isolates in the period 2012-2015. 4.116 environmental samples collected between October 2012 - March 2014, 35 were positive or C. neo mans var. grubii. From 55 cryptococcosis cases reported in Bogotá during 2012-2015, 49 isolates were ecover d. From those, 94\% were identified as C. neoformans var. grubii molecular type VNI; 4\% as VNII and $2 \%$ coformans var neoformans VNIV. The 84 detected clinical and environmental isolates studied had a milar between 49-100\% according with molecular typing. The correlation between environmental and clinic mples a firms the hypothesis that patients acquire the disease from environmental exposure to the fungal propagules.
\end{abstract}

Key words: Cryptococcus neoformans - cryptococcosis - e ro Colombia

Cryptococcosis is an opportunistic mycoses of immunosuppressed and immunocompetent patients. Infection is acquired by inhalation of fungal propagules through environmental exposure. It is considered a potentially fatal infection of the lungs and the central nervour ystem (CNS). The etiological agents are Cryptococcu formans and C. gattii, whose varieties have a orldh be distribution. However, a recently proposed $\Lambda$ omy fo. these species suggests there are seven species in $t$ complex (Cabral 1999, Cogliati 2013, Hag cel al. 2015).

There are two varieties of $C$. neo, rman nainly associated with HIV/AIDS patients, val $/$ (serotype A), distributed worldwide and D) that together with the hybn $V$, are concentrated in Europe (Viviani et a' 06, 1les et al. 2008, Heitman et al. 2011). Thes spe es have been isolated mostly from bird excreta esp ally rom pigeon, and decaying wood from fferent ex, except for the serotype D (Rosario et dil. 28 , Trilles et al. 2008, Francis et al. 2013). Sty es on the nvironmental distribution in different $\mathrm{p}$ s c che world have increased, such as in South Africa, A ntir , Brazil, India and Thailand (Ergin et al $-0, \mathrm{Ku}_{\mathrm{L}}$ et al. 2004, Grover et al. 2007, Rosae 0 , Trilles et al. 2008, Refojo et al. 2009). C. tii is grouped into serotypes $\mathrm{B}$ and $\mathrm{C}$, distributed

doi: 10.1590/0074-02760160201

Financial support: Instituto Nacional de Salud, Departamento Administrativo de Ciencia, Tecnología e Innovación Colciencias (grant $\mathrm{n}^{\circ}$ 2011-3600115683).

+ Corresponding author: pescandon@ins.gov.co

Received 13 May 2016

Accepted 16 July 2016 in tropical, rbtropical and template regions (Byrnes et 2009, Cogliati 2013), and affecting mostly immunoco petent persons. This species has been recovered rom ant debris in trees like Eucalyptus sp, Terminalia spa, Corymbias, among others. C. gattii has been reported in recent years in Australia, Italy, Spain, Netherlands, Japan, India, Colombia and South Korea (Granados \& Castañeda 2006, Grover et al. 2007, Hagen \& Boekhout 2010, Escandón et al. 2010, Colom et al. 2012, Hagen et al. 2012, Cogliati 2013).

In Colombia, environmental studies have reported isolates of C. neoformans var. grubii (serotype A) and C. gattii (serotype B and serotype C) from plant debris in trees like Eucalyptus sp, T. catappa, Corymbias and Ficus, and described that serotypes A and B were the most prevalent (Castañeda \& Castañeda 2001, Granados \& Castañeda 2005, Quintero et al. 2005, Escandón et al. 2010). In Bogotá, studies reported C. neoformans and $C$. gattii from 192 environmental and clinical samples, being serotype A the most prevalent, followed by serotype B and C (Ordoñez \& Castañeda 1994).

In 2001, Castañeda and Castañeda (2001) described the association between Cryptococcus and Eucalyptus from a local park in Bogotá, with a positivity of $4 \%$ during a two-year sampling period. In 2005, Granados and Castañeda (2005) collected 480 environmental samples with a positivity of $7.9 \%$ for C. neoformans and, in 2010, Escandón et al. (2010) found a positivity of $11.7 \%$ for $C$. gattii isolated from Corymbia ficifolia in Bogotá.

A number of molecular typing techniques have been used to study the molecular epidemiology of $C$. neoformans and C. gattii (Meyer et al. 2003), providing more discriminatory power than conventional techniques (Perfect et al. 1993). Using polymerase chain reaction (PCR) fingerprinting, eight major molecular types have 
been established (Meyer et al. 2003). The major molecular types VNI and VNII correspond to C. neoformans var. grubii, being VNI the most prevalent in environmental and clinical isolates (Springer \& Chaturvedi 2010, Cogliati 2013), VNIII corresponds to the AD hybrid and VNIV (Serotype D) corresponds to C. neoformans var. neoformans, found mainly in Europe (Viviani et al. 2006).

Molecular types VGI, VGII, VGIII and VGIV correspond to C. gattii, whose environmental and clinical distribution vary according to the region. It has been reported that molecular type VGI is the most frequent in Australia (Meyer et al. 2003); VGII in Canada, South America and Australia (Byrnes et al. 2009, Cogliati 2013), being the unique to report of an outbreak in Vancouver Island and in the North of USA (Byrnes et al. 2009); VGIII is most frequently recovered in South America (Meyer et al. 2003) and VGIV in South Africa and India (Springer \& Chaturvedi 2010, Cogliati 2013).

In the last report of the Colombian Group for the Study of cryptococcosis, the annual incidence rate was $3.3 \times 10^{3}$ cases in AIDS patients and in the general population $2.4 \times 10^{6}$, between 2006-2010. This passive surveillance is important for the study of this opportunistic infection in AIDS patients, considered a sentinel marker for HIV infection (Escandón et al. 2012). The aim of this work was to determine the presence of $C$. neoformans and C. gattii in the environment in Bogotá and to establish the genetic relation of these isolates with those causing cases of cryptococcosis reported during the period 2012-2015.

\section{MATERIALS AND METHODS}

Study design - Epidemiological and molecula from environmental and clinical isolates in $t^{1}>\mathrm{ca}_{\mathrm{p}} \mathrm{d}$ city Bogotá - Colombia.

Study area - Bogotá is the capital colomo located at $4^{\circ} 34 \mathrm{~N}$ latitude, $74^{\circ} 00 \mathrm{~W}$ lo gitude, and 2.630 meters above sea level, with an aver tem erature of $13.8^{\circ} \mathrm{C}$. A total of 15 areas were chose divided in six zones from north to south i vorá. Four areas previously determined to be posit , Granados \& Castañeda 2005, Escandón e 1. 010) ere included, and the others were chosen de to ixh density of trees (Fig. 1).

Clinical isol es - Prmation on cryptococcosis cases was gath ec trospectively from a passive surveillance durin 2012-20. from patients residing in Bogotá.

Env nn intalsampling - The methodology used for sampling d cribed by Escandón et al. (2010). Enviro ne al sa ples from the hollows, leaves, bark, flowfruits of two tree species, Eucalyptus sp. and Con bia sp., were collected during every month between september 2012 and March 2014 ( $\mathrm{n}=19$ months), in the selected areas previously described. A longitudinal sampling was carried out in those positive areas for a period of five months from October 2013 - March 2014.

Environmental data - Temperature, relative humidity, precipitation and sunshine in Bogotá during the study period were obtained from the Institute of Hydrology, Meteorology and Environmental Studies (http://www.ideam.gov.co.).
Conventional techniques - Environmental samples were identified by streaking onto Niger-seed agar as described by Granados and Escandón (Granados \& Castañeda 2006, Escandón et al. 2010). Phenotypic tests were used for sample processing and confirmation of isolates as previously described (Kwon-Chung et al. 1982). DNA was extracted as reported by Escandón et al. (2006) and molecular type was determined by PCR fingerprinting with the unique primer $(\mathrm{GTG})_{5}$ and restriction fragment length polymorphism (RFLP) of the URA5 gene Meyer et al. 2003, Escandón et al. 2010). PCR prod ts vere compared with reference strains reported and "vide by Meyer et al. (2003).

The analysis of molecular types ge rated by $\mathrm{CR}$ $(\mathrm{GTG})_{5}$ was performed using the Gel-Con, re V.4.0 (Applied Maths, Sint-Martens atem, Betsum) program. The Dice coefficient was $u$ do to mpare the molecular types and establish go tic nships between isolates. Clustering was ased the Unweighted Pair Group Method (UPC algorm with a tolerance $4.0 \%$ and optimisation of 1 ,

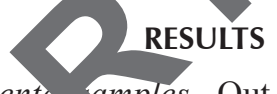

Environmenta amples - Out of 4.116 environmental samples Corymbia $s p$ and Eucalyptus $s p$ in Bogotá different zones (Fig. 1), 35 samples were positi for C. neoformans $(0.9 \%)$. Of these positim samples, 20 (57.1\%) were from bark, 13 (37.1\%) from soil d two (5.8\%) from fruit (Table I). From the posive s hples, 110 colonies were recovered all belonging neoformans var. grubii. C. gattii was not recovered. Most of the positive samples $(n=27)$ were obtained In July and November 2013, coinciding with previous periods of high precipitation. Only few samples $(n=8)$ were recovered during the dry season temperature and relative humidity was relatively constant throughout the study period with no other obvious associations (Fig. 2).

Description of clinical cases of cryptococcosis - A total of 55 surveys were received during the study period, corresponding to new cases of cryptococcosis, reported mainly in men (43 cases, 78.2\%). Patients aged 16-79 years old were the most affected $(59.3 \%$ of the cases with a

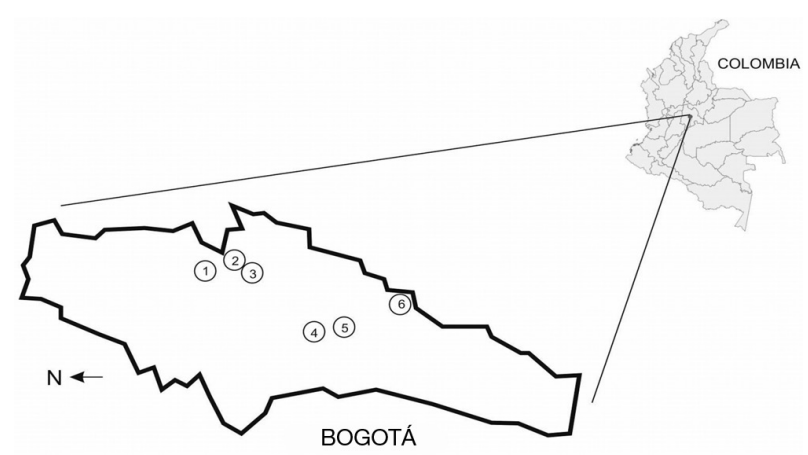

Fig. 1: description of the sampled areas for the recovery of Cryptococcus neoformans, recovered between October 2012 and March 2014 in the capital city of Colombia, Map of Bogotá with the six zones. 
median of 43 years). The main risk factor was HIV infection in $36(65.5 \%)$ cases, other risk factors were diabetes and leukemia and chronic renal failure. One patient presented with autoimmune disease (lymphoma) (Table II).

The most common clinical manifestations are described in Table II, consisting mostly of headache and fever.

From the patients, $47.2 \%$ were treated with antifungal agents, with amphotericin $\mathrm{B}$ being the most common antifungal used (47.3\%), followed by fluconazole (5.5\%). Neurocryptococosis was the most common clinical form of the disease. Laboratory diagnosis was performed using the conventional methods of direct examination, antigenemia and culture. In 49/55 cases, the isolate was recovered; in six cases it was not possible to recover the strain and only medical history is described (Table II).

Molecular characterisation - Molecular type determination revealed that from the 84 isolates characterised ( $\mathrm{n}=49$ clinical and $\mathrm{n}=35$ environmental), 79 isolates (94\%) were C. neoformans var. grubii molecular type VNI, 4 (4.8\%) isolates VNII and 1 (1.2\%) VNIV (Fig. 3).

Of the two main groups identified, group I had a similarity of $48 \%$, including isolates of C. neoformans var. grubii molecular type VNI and VNII. A subgroup of group 1 was identified, with an index of similarity between $50-100 \%$, containing all isolates belonging to the molecular type VNI. In subgroup A, 10 genetically indistinguishable clusters were identified (with $100 \%$ similarity), containing five clusters of clinical and environmental isolates. Group II contained the only VNIV clinical late recovered and the control strain with a $100 \%$ similarity. Four clinical and one environmental isolates did not group with any of the other isolates (Fig. 4).

\section{DISCUSSION}

In Colombia, several studies have been performed to describe the environmental importance of Cryptococcus, and the potential relation of environmental and clinical isolates. In some of these studies, isolates of serotypes $\mathrm{A}, \mathrm{B}$ and $\mathrm{C}$ have been recovered, from lifferent species of trees including Eucalyptus sp $u c y s p$, C. ficifolia, T. catappa, among others, similâ do th reports of other groups in countries like Brazil an a (Randhawa et al. 2001, Trilles et al. 200

C. neoformans var. grubii sero A a only species recovered in the environn ntal sampus collected in this study, with a frequency o $0.7 \%$ This positivity falls within that of the literan a frequency between $0.1-69 \%$ has beer eport confirming the same results obtained in oth ironmental studies, and reinforcing the predominance $\partial_{1}$ is species in the environment around th woll (Perfect et al. 1993, Randhawa et al. 2001, Escano 06 , Trilles et al. 2008).

In this study of found C. neoformans in places with high den trees, people and pigeons, distributed in the center north-west of the city. In other studies of Bogotá, aut rs reported a positivity from the environin $7.9 \%$ for C. neoformans (Granados \& Castañeda 2005) The yeast was recovered in five out of the six udi $d$ areas, and from those, four were previously re-

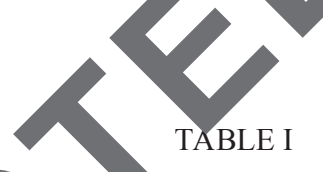

Description of positive samples fo ptococcu neoformans recovered between October 2012 and March 2014 in the capital cit of Cole pia, according to the type of tree and type of sample

\begin{tabular}{|c|c|c|c|c|c|c|c|}
\hline \multirow[b]{2}{*}{ Zones } & \multirow[b]{2}{*}{ Places } & \multirow[b]{2}{*}{ of samples } & \multirow{2}{*}{$\frac{\text { Corymbia sp }}{\text { Bark }}$} & \multicolumn{4}{|c|}{ Eucalyptus } \\
\hline & & & & Bark & Fruit & Soil & Total \\
\hline \multirow[t]{3}{*}{ Zone 1} & & 4 & 0 & 0 & 0 & 0 & 0 \\
\hline & & 165 & 0 & 2 & 0 & 0 & 2 \\
\hline & & 10 & 0 & 0 & 0 & 0 & 0 \\
\hline \multirow[t]{8}{*}{ Zone $2^{*}$} & & 3 & 0 & 0 & 0 & 0 & 0 \\
\hline & & 26 & 0 & 0 & 0 & 0 & 0 \\
\hline & $7-94$ & 190 & 0 & 1 & 1 & 3 & 5 \\
\hline & Once & 707 & 1 & 0 & 0 & 0 & 1 \\
\hline & achivaches $85-105$ & 21 & 0 & 0 & 0 & 0 & 0 \\
\hline & Virrey & 26 & 0 & 0 & 0 & 0 & 0 \\
\hline & Gobernación & 801 & 1 & 1 & 0 & 2 & 4 \\
\hline & Maloka & 1027 & 0 & 14 & 0 & 7 & 21 \\
\hline \multirow[t]{2}{*}{ Zone $5^{*}$} & Parque de los Novios & 184 & 0 & 0 & 1 & 1 & 2 \\
\hline & Universidad Nacional & 922 & 0 & 0 & 0 & 0 & 0 \\
\hline \multirow[t]{2}{*}{ Zone 6} & Candelaria & 26 & 0 & 0 & 0 & 0 & 0 \\
\hline & Plaza de Bolívar & 4 & 0 & 0 & 0 & 0 & 0 \\
\hline Total & & 4116 & 2 & 18 & 2 & 13 & 35 \\
\hline
\end{tabular}

*: places which had been positive in previous studies. 


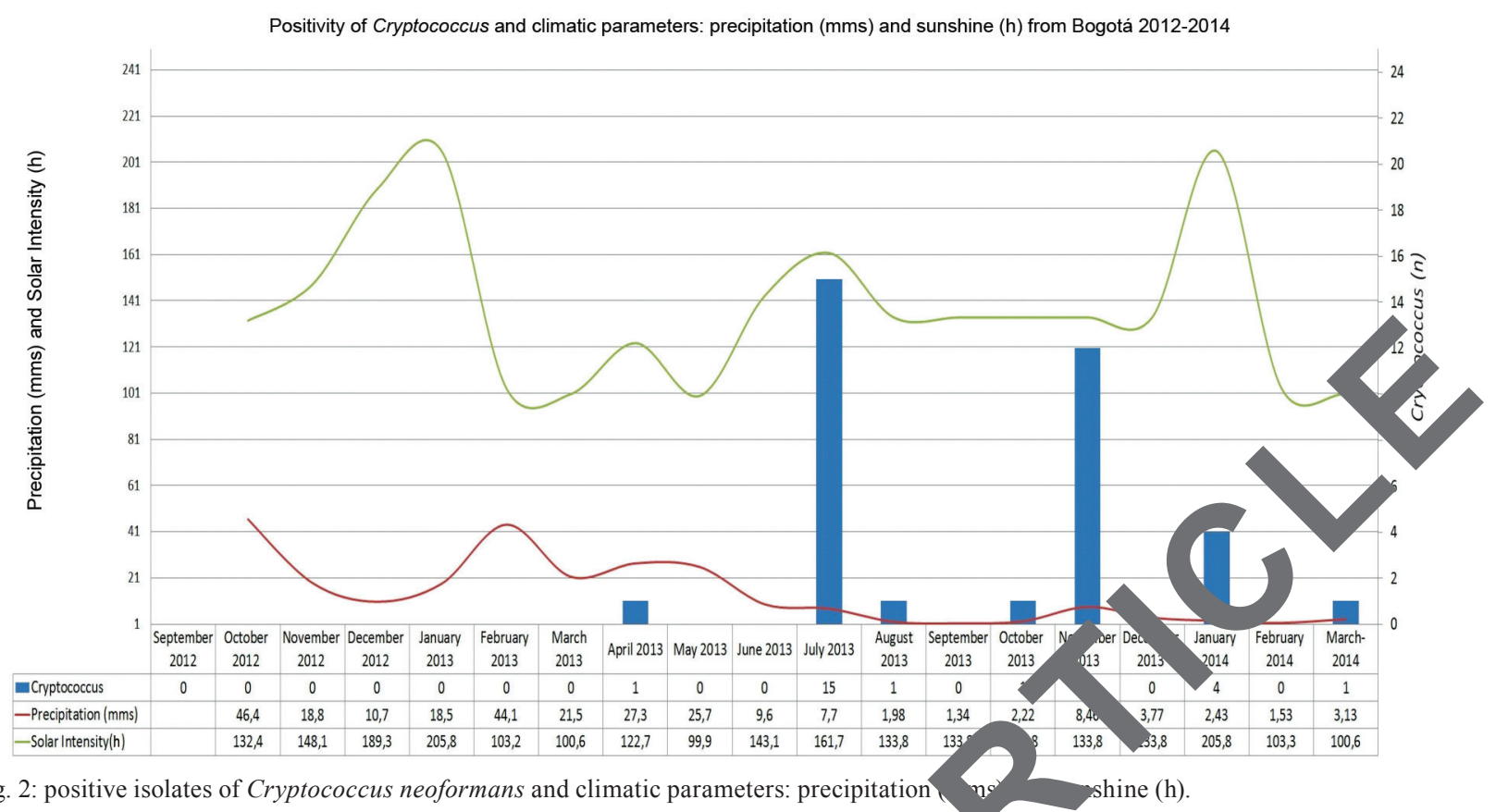

Fig. 2: positive isolates of Cryptococcus neoformans and climatic parameters: precipitation shine (h).

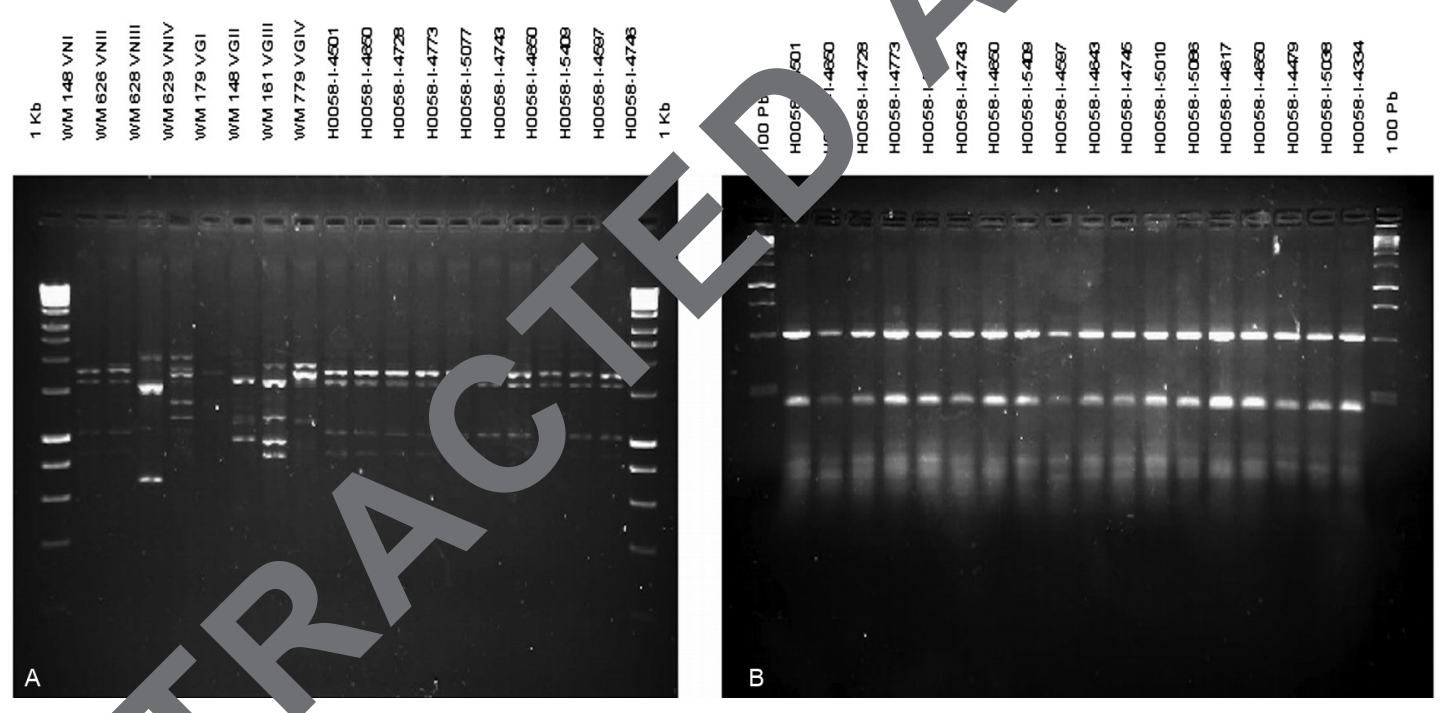

Fig. 3: characterisa on o inical and environmental isolates of Cryptococcus neoformans typed by $\mathrm{GTG}_{5}$-PCR fingerprinting (A) and RFLP-URA5 (B).

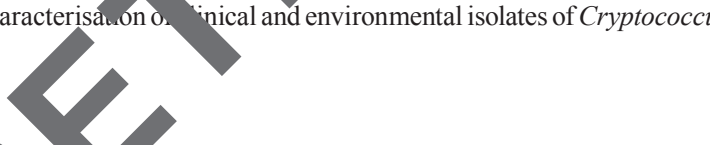

po po in other studies (Escandón et al. 2006, anz ac \& Castañeda 2006), suggesting permanence an olonssation of the fungus over time. Additionally, a nem rea was identified as positive for C. neoformans.

In this study $C$. gattii was not recovered, from clinical nor environmental samples, which is in contrast to other studies reported in Bogotá were $C$. gattii was isolated in $11.72 \%$ from $C$. ficifolia samples (Escandón et al. 2010).

This study reinforces the predominance of $C$. neoformans in Eucalyptus tree species; as has been found in studies in Egypt (Cogliati 2013), Brazil (Trilles et al. 2008) and Australia (Ellis \& Pfeiffer 1990). The preference of $C$. neoformans for this type of tree may be due to the specific characteristics of the wood, for example due to the hollows, as suggested by Ellis and Pfeiffer (1992).

The months when the fungus was recovered coincide with previous periods of high precipitation, confirming the findings reported by Granados and Castañeda (2005, 2006), who analysed the presence of $C$. neoformans in environmental samples and concluded that the fungus was most frequently recovered in the rainy season.

In Colombia, cryptococcosis by $C$. neoformans var. grubii has high morbidity and mortality, especially in HIV-positive patients in (Escandón et al. 2010, Lizarazo et al. 2014). Chronic lung disease, cancer and immune disorders such as neoplasia, HIV/AIDS, predispose pa- 


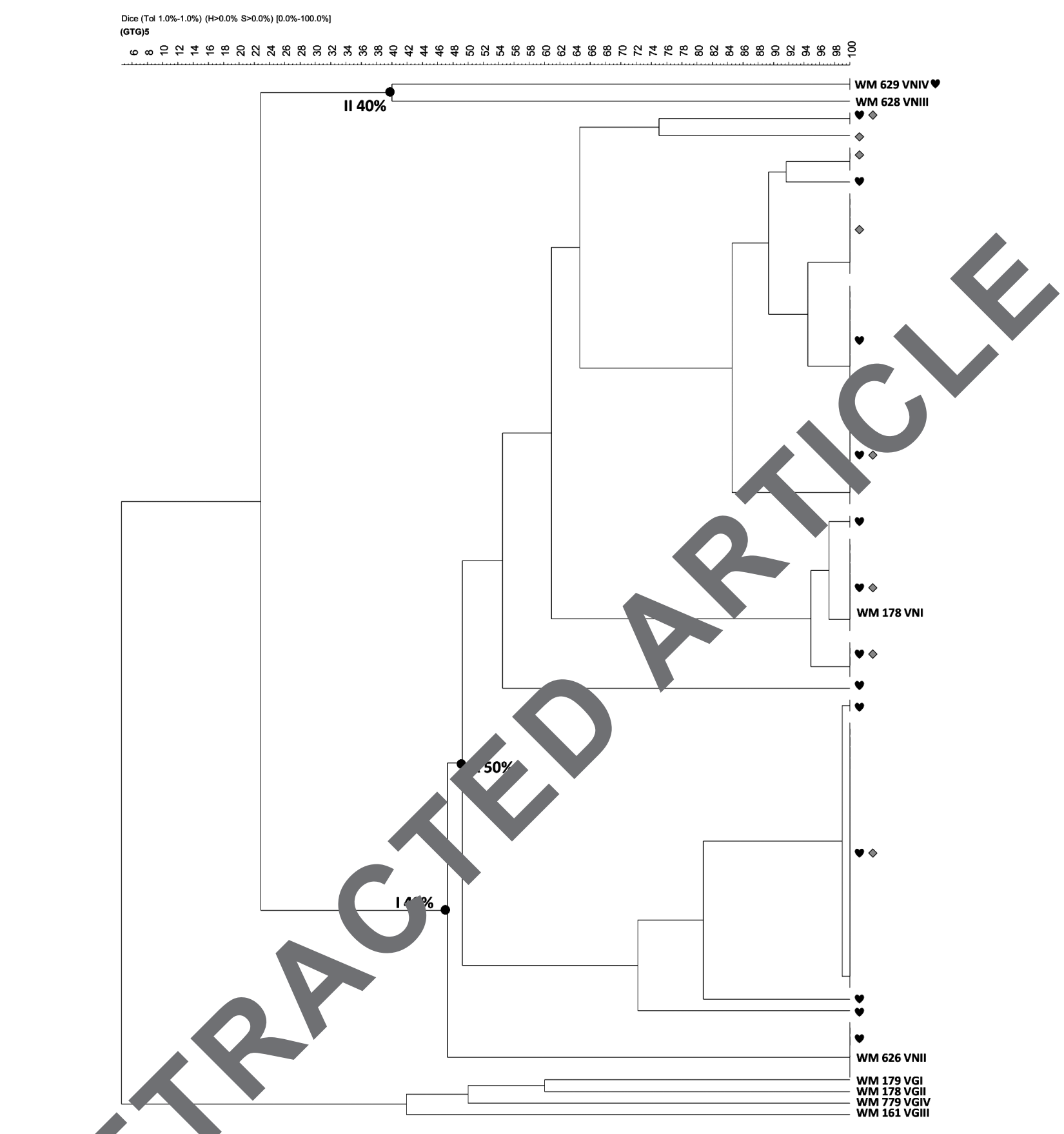

Fig. 4: GT PC fingerprinting dendrogram of the Cryptococcus neoformans clinical and environmental isolates from Bogotá. Dendrogram of the PCh erpri from clinical ( $\bullet$ and environmental isolates ( $\diamond$, Group (A), clinical and environmental isolations grouped with $100 \%$ sim ind 1.5 .

tients infection by Cryptococcus (Hull \& Heitman 2002). The latter is apparent in Colombian patients, in which risk factors such as HIV infection, leukemia, diabetes and renal failure were presented (Escandón et al. 2010), as well as the predominance of $C$. neoformans var. grubii (serotype A) (98.1\%). The finding in Colombia that var. grubii is the most common clinical isolate correlates with the reports from around the world, as well as the association of molecular type VNI with AIDS patients (Escandón et al. 2006).
Genotype VNI was identified in $94 \%$ of the environmental and clinical isolates, in agreement with the distribution reported in South America (Meyer et al. 2003), Vietnam (Chau et al. 2010), India (Jain et al. 2005), Malaysia (Tay et al. 2010), China (Feng et al. 2008), Korea (Choi et al. 2010) and frequently recovered in the environment (Jain et al. 2005, Cogliati 2013). Molecular studies found a relation between clinical and environmental isolates, reinforcing the hypothesis that infection is acquired by the inhalation of infectious propagules 


\section{TABLE II}

Clinical manifestations, pharmacological treatment and diagnosis of Cryptococcosis cases in Bogotá, Colombia (2012-2015)

\begin{tabular}{lcc}
\hline Characteristics & (n) & $(\%)$ \\
\hline Sex & & \\
Male & 43 & 78.2 \\
Female & 12 & 21.8 \\
Clinical features & & \\
Headache & 45 & 81.8 \\
Fever & 28 & 50.9 \\
Nausea and vomiting & 21 & 38.2 \\
Confusion & 18 & 32.7 \\
Loss weight & 17 & 30.9 \\
Seizures & 13 & 23.6 \\
Meningeal signs & 7 & 12.7 \\
Cough & 13 & 23.6 \\
Visual alterations & 8 & 14.5 \\
Risk factors & & \\
HIV infection & 36 & 65.5 \\
Corticosteroids & 4 & 9.1 \\
Autoimmune disease & 1 & \\
Diabetes & 1 & 5.4 \\
Others (leukemia, CT) & 2 & \\
No risk factor & 11 & 20 \\
Type & &
\end{tabular}

Type of diagnosis

Positive Culture(one strain was not viable)*

Positive Culture and Antigen

Positive Culture and direct examination

Positive Culture, direct examination and Antige

Direct examination

Direct examination and antigen

Total

Type of antifungal used

Amphotericin B

Fluconazole

Combined

No theraphy
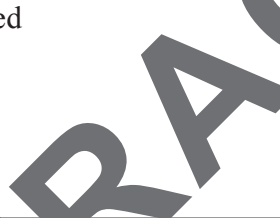

*: it was not possi to rec $r$ the strain.

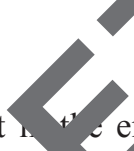

present en ironment (Meyer et al. 2003, Trilles

this study, clinical and environmental isolates were fo co ou between $48-100 \%$ similar. This is congruent with her studies around the world, such as the reported in 2008 by Trilles et al. (2008), who found a similarity index of 50\% in VNI, being the most prevalent in 443 environmental and clinical isolates from Brazil. In the same year Meyer reported a similarity index of $50.4 \%$ between clinical and environmental isolates of $C$. neoformans var. grubii (Meyer et al. 2003).

The search of $C$. neoformans and $C$. gattii in the environment needs to be included as a routine practice, in those areas were cryptococcosis cases are prevalent, as a tool that will help us identify colonised areas which may represent increased exposure risks to the patients. The continuous finding of the fungus both in the environment and in the patients of the capital city of Colombia reinforces the need to direct our efforts into more active surveillance of the disease.

Ecological studies are relevant in the epidemiological study of this pathogen; therefore the continuity of clinical research is important for ecological studies, the results of which may allow us to determinate areas where th fungus can find favorable conditions to develop in son sia.

\section{ACKNOWLEDGEMENTS}

To Paola Castillo, for designing Figure f the manuscript and Colombian Cryptococcosis Study Group.

Byrnes E, Bildfell R, Frank S, Mitcl yo To Heitman J. Molecular evidence that the rap of Vancouver Island outbreak of Cryptococcus gattii infe nhas $\mathrm{ex}_{\mathrm{N}}$ ded into the Pacific Northwest in the United Stat A sect Dis. 2009; 199(7): 1081-6.

Cabral LF. Wood, ani nd huma, beings as reservoirs for human Cryptococcus ofor ans infection. Rev Iberoam Micol. 1999; 16(2): 77-81.

Castañeda Astañedà Aislamiento de especies de Cryptococcus asociad co. glyptus en un parque de Bogotá. Biomedica. 2001; 21.

T, Mai Phu N, Nghia H, Chuong L, Sinh D, et al. A proctive descriptive study of cryptococcal meningitis in HIV un fected patients in Vietnam - high prevalence of Cryptococneoformans var. grubii in the absence of underlying disease. MC Infect Dis. 2010; 10: 199-210.

hoi YH, Ngamskulrungroj P, Varma A, Sionov E, Hwang SM, Carriconde F, et al. Prevalence of the VNIc genotype of Cryptococcus neoformans in non-HIV- associated cryptococcosis in the Republic of Korea. FEMS Yeast Res. 2010; 10(6): 769-78.

Cogliati MM. Global molecular epidemiology of Cryptococcus neoformans and Cryptococcus gattii: an atlas of the molecular types. Scientifica. 2013; 2013: 23 pp.

Colom MF, Hagen F, González A, Mellado A, Morera N, Linares C, et al. Ceratonia siliqua (carob) trees as natural habitat and source of infection by Cryptococcus gattii in the Mediterranean environment. Med Mycol. 2012; 50(1): 67-73.

Ellis D, Pfeiffer T. Ecology, life cycle and infectious propagule of Cryptococcus neoformans. Lancet. 1990; 336(8729): 923-5.

Ellis D, Pfeiffer T. The ecology of Cryptococcus neoformans. Eur J Epidemiol. 1992; 8(3): 321-5.

Ergin C, Ilkit M, Kaftanoglu O. Detection of Cryptococcus neoformans var. grubii in honeybee (Apismellifera) colonies. Mycoses. 2004; 47(9-10): 431-4.

Escandón P, de Bedout C, Lizarazo J, Agudelo CI, Tobón A, Bello S, et al. Cryptococcosis in Colombia: results of the national surveillance program for the years 2006-2010. Biomedica. 2012; 32(3): 386-98.

Escandón P, Sánchez A, Firacative C, Castañeda E. Isolation of Cryptococcus gattii molecular type VGIII, from Corymbia ficifolia detritus in Colombia. Med Mycol. 2010; 48(4): 675-8.

Escandón P, Sánchez A, Martínez M, Meyer W, Castañeda E. Molecular epidemiology of clinical and environmental isolates of the Cryptococcus neoformans species complex reveals a high genetic diversity and the presence of the molecular type VGII mating type a in Colombia. FEMS Yeast Res. 2006; 6(4): 625-35. 
Feng X, Yao Z, Ren D, Liao W, Wu J. Genotype and mating type analysis of Cryptococcus neoformans and Cryptococcus gattii isolates from China that mainly originated from non-HIV-infected patients. FEMS Yeast Res. 2008; 8(6): 930-8.

Francis X, Auxilia A, Kannan M, Freeda A, Senthil S. Isolation and identification of Cryptococcus neoformans from pigeon droppings in Tiruchirappalli district of Tamil Nadu, South India. Int J Curr Microbiol App Sci. 2013; 11(2): 404-9.

Granados D, Castañeda E. Influence of climatic conditions on the isolation of members of the Cryptococcus neoformans species complex from trees in Colombia from 1992-2004. FEMS Yeast Res. 2006; 6(4): 636-44.

Granados D, Castañeda E. Isolation and characterization of Cryptococcus neoformans varieties recovered from natural sources in Bogotá, Colombia, and study of ecological conditions in the area. Microb Ecol. 2005; 49(2): 282-90.

Grover N, Nawange S, Naidu J. Ecological niche of Cryptococcus neoformans var. grubii and Cryptococcus gattii in decaying wood of trunk hollows of living trees in Jabalpur City of Central India. Mycopathologia. 2007; 164(4): 159-70.

Hagen F, Boekhout T. The search for the natural habitat of Cryptococcus gattii. Mycopathologia. 2010; 170(4): 209-11.

Hagen F, Colom MF, Swinne D. Autochthonous and dormant Cryptococcus gattii infections in Europe. Emerg Infect Dis. 2012; 18(10): 1918-24.

Hagen F, Khayhan K, Theelen B, Kolecka A, Polacheck I, Sionov E, et al. Recognition of seven species in the Cryptococcus gattii/ Cryptococcus neoformans species complex. Fungal Genet Biol. 2015; 78: 16-48.

Heitman J, Kozel TR, Kwon-Chung KJ, Perfect JR, Casade it A Cryptococcus: from human pathogen to model yeast. Was (DC): ASM Press; 2011. p. 565-84.

Hull C, Heitman J. Genetics of Cryptococcus neoformans, nnu Rev Genet. 2002; 36: 557-61.

Jain N, Wickes BL, Keller SM, Fu J, Casa vall A ain P, et al. Molecular epidemiology of clinical Cry coccl neoformans strains from India. J Clin Microb ${ }^{-1}$ 2005; 45, , 5733-42.

Kuroki M, Phichaichumpon C, Yasuo cranairadul P, Chosa T, Sirinirund P, et al. En men isolation of Cryptococcus neoformans from an em region $\mathrm{f}$ HIV-associated cryptococcosis in Thailand. $1(10): 809-12$.
Kwon-Chung KJ, Polacheck I, Bennet J. Improved diagnostic medium for separation of Cryptococcus neoformans var. neoformans (serotypes A and D) and Cryptococcus neoformans var. gattii (serotypes B y C). J Clin Microbiol. 1982; 15(3): 535-7.

Lizarazo J, Escandón P, Agudelo CI, Castañeda E. Cryptococcosis in Colombian children and literature review. Mem Inst Oswaldo Cruz. 2014; 109(6): 797-804.

Meyer W, Castañeda A, Jackson S, Huynh M, Castañeda E, Iberoamerican Cryptococcal Study Group. Molecular typing of Iberoamerican Cryptococcus neoformans isolates. Emerg Infect Dis. 2003 ; 9(2): 189-95.

Ordoñez N, Castañeda E. Serotipificación de aislamie del medio ambiente de Cryptococcus neoformans en Biomedica. 1994; 14(3): 131-9.

Perfect J, Ketabchi N, Cox G, Ingram CW, Beise 'L. K Jotyping of Cryptococcus neoformans as an cumiolog Clin Microbiol. 1993; 31(12): 3305-9.

Quintero E, Castañeda E, Ruiz Env nm al distribution of Cryptococcus neoformans the partment of Cundinamarca, Colombia. Rev Iberoam col. 200, 2(2): 93-8.

Randhawa H, Mussa AY, Khan U. Decaying wood in tree trunk hollows as a n? substrat ior Cryptococcus neoformans and other yea sike ingi of clinical interest. Mycopathologia. 2001; 151(2):

Refojo N, P tra D, Bn y M. Isolation of Cryptococcus neoformans and $\mathrm{Cr}$, oce gattii from trunk hollows of living trees in Buenos Aire , Argentina. Med Mycol. 2009; 47(2): 177-84.

Rosario I, Aco B, Colom F. La paloma y otras aves como reservorio Cryptococcus spp. Rev Iberoam Micol. 2008; 25: 13-8.

Spring D, Chaturvedi V. Projecting global occurrence of Cryptocus gattii. Emerg Infect Dis. 2010; 16(1): 14-20.

Tay ST, Rohani MY, Hoo TS, Hammimah H. Epidemiology of cryptococcosis in Malaysia. Mycosis. 2010; 53(6): 509-51.

Trilles L, Lazéra MS, Wanke B, Oliveira RV, Barbosa GG, Nishikawa $\mathrm{MM}$, et al. Regional pattern of the molecular types of Cryptococcus neoformans and Cryptococcus gattii in Brazil. Mem Inst Oswaldo Cruz. 2008; 103(5): 455-62.

Velagapudi R, Hsueh YP, Geunes-Boyer S, Rae J, Heitman J. Spores as infectious propagules of Cryptococcus neoformans. Infect Immun. 2009; 77(10): 4345-55.

Viviani M, Cogliati M, Esposto M. Molecular analysis of 311 Cryptococcus neoformans isolates from a 30-month ECMM survey of cryptococcosis in Europe. FEMS Yeast Res. 2006; 6(4): 614-9. 